\title{
Stock Market Investors: Who Is More Rational, and Who Relies on Intuition?
}

\author{
Shlomit Hon-Snir \\ Economics and Management Department \\ The Max Stern Academic College of Emek Yezreel, Emek Yezreel \\ Emek Yezreel 19300, Israel \\ E-mail: shlomith@yvc.ac.il \\ Andrey Kudryavtsev (Corresponding author) \\ Economics and Management Department \\ The Max Stern Academic College of Emek Yezreel, Emek Yezreel \\ Emek Yezreel 19300, Israel \\ E-mail: andreyk@yvc.ac.il
}

Gil Cohen

Economics and Management Department

The Max Stern Academic College of Emek Yezreel, Emek Yezreel

Emek Yezreel 19300, Israel

E-mail: gilc@yvc.ac.il

Received: February 29, 2012

Accepted: March 12, $2012 \quad$ Published: May 1, 2012

doi:10.5539/ijef.v4n5p56

URL: http://dx.doi.org/10.5539/ijef.v4n5p56

\begin{abstract}
Contemporary research documents various psychological aspects of economic and financial thought and decision-making. The main goal of our study is to analyze the effects of five well-documented behavioral biases, namely, disposition effect, herd behavior, availability heuristic, gambler's fallacy and hot hand fallacy, on the mechanism of stock market decision-making, and, in particular, the individual differences in the degrees of these effects. Employing an extensive online survey, we document that on average, active stock market investors exhibit moderate degrees of behavioral biases. Furthermore, we find that, on the one hand, more experienced investors are less affected by behavioral patterns, yet, on the other hand, professional portfolio managers do not behave, in this respect, differently (more rationally) from non-professional investors. We, therefore, infer that investor's experience in stock market matters, but not the "status" itself of being a professional, may decrease the effect of behavioral biases on her. In addition, we detect that the major "rationalizing" effect of experience is already accumulated in the first years of investors' stock market activity. Finally, we document that female investors are more strongly affected by all the five behavioral biases.
\end{abstract}

Keywords: Availability Heuristic, Behavioral finance, Disposition effect, Gambler's fallacy, Herd behavior, Hot hand fallacy, Individual differences

JEL Classification: D81, D84, G11, G14, G19.

\section{Introduction}

Human judgments fall prey to a variety of systematic biases and distortions that may result in "incorrect" patterns of behavior and inferior performance (for an overview, see, for example, Kahneman, et al. (1982), Stracca (2004)). In this study we analyze the effect of five well-documented behavioral biases on market investors' decision-making, and in particular, we wish to shed light on the nature of the individual differences in the magnitudes of these biases, the matter which is almost not discussed in previous financial literature. 
The behavioral patterns (biases) we analyze are:

Disposition effect (Shefrin and Statman (1985)) - investors' tendency to sell stocks that gained value and to hold on to stocks that lost value.

Herd behavior (for a recent survey, see, e.g., Hirshleifer and Teoh (2003)) - behavior of an investor imitating the observed actions of others or the movements of market instead of following her own beliefs and information.

Availability heuristic (Tversky and Kahneman (1973)) - phenomenon of determining the likelihood of an event according to the easiness of recalling similar instances.

Gambler's fallacy (Laplace (1796)) - incorrect belief in negative autocorrelation of non-autocorrelated random sequences.

Hot hand fallacy (Gilovich, Vallone and Tversky (1985)) - incorrect belief that certain random sequences may in fact be non-random (human-related) and therefore, positively autocorrelated.

We perform an online survey asking stock market investors, both professional and non-professional, a number of questions concerned with their personal way of making investment decisions. The questions are formulated so as to detect if the participants are affected by the above-mentioned biases. For each participant, we calculate her personal "bias grades", which are higher the more her reported behavior, as appears from her answers, is consistent with the respective behavioral effects. On average, our survey participants exhibit moderate degrees of behavioral biases.

Furthermore, as a major focus of our research, we analyze the individual differences in the "bias grades". First of all, we document that professional portfolio managers are just non-significantly weaker affected by the behavioral patterns, than non-professional investors. On the other hand, we find that the magnitude of the biases is significantly lower for more experienced investors. Moreover, professional investors appear to be significantly stronger influenced by the behavioral effects, than non-professional but experienced investors. Thus, we infer that investor's experience in stock market matters, but not the "status" itself of being a professional, may decrease the effect of behavioral biases on her. Also in this context, we detect that the major "rationalizing" effect of experience is already accumulated in the first years of investors' stock market activity.

Finally, we document that female investors are more strongly affected by all the five behavioral biases. This result may be potentially explained in the framework of psychological literature, showing that women are, on average, more driven by feelings and emotions and more willing to follow the ideas suggested by others, while men are more assertive and independent in their thoughts and actions (see for example, Feingold (1994), Helgeson (1994, 2003), Fritz and Helgeson (1998)).

The rest of the paper is structured as follows. In Section 2, we review the literature on behavioral biases, featuring both psychological aspects and economic applications. In Section 3, we describe our survey design and research approach. Section 4 defines our hypotheses and provides the empirical tests and the results. Section 5 concludes and provides a brief discussion.

\section{Psychological Biases in Finance: Literature Review}

Recent literature demonstrates that economic and financial behavior and decision-making may be affected by various psychological effects. These effects, often referred to as "biases" or "fallacies", are based on feelings, emotions and intuition, rather then on rational considerations, and often result in inferior financial performance. In present research, we concentrate on five well-documented effects.

\subsection{Disposition Effect}

One of the most striking behavioral patterns is the tendency of investors to sell "winners" (stocks that gained value) and to hold on to "losers" (stocks that lost value). The term "disposition effect" is first dubbed by Shefrin and Statman (1985), who also offer a behavioral explanation for it, based on the combination of loss aversion (Kahneman and Tversky (1979)) and mental accounting (Thaler (1985)). In essence, the disposition effect is a reflection of investors keeping a separate mental account for each stock and, according to prospect theory, maximizing an S-shaped (concave for gains and convex for losses), reference-level based, value function within that account. Three different kinds of data are applied for studying the disposition effect: aggregate (on the level of stock exchanges), individual (on the level of individual investors) and experimental.

The first to employ aggregate data are Lakonishok and Smidt (1986). Using historical stock prices as possible reference points, they find that winners tend to have higher abnormal volume than losers. A similar technique is employed by Ferris et al. (1988) and Bremer and Cato (1996), yielding comparable results. Huddart et al. (2007) find that a significantly higher volume when stock prices are above (below) their fifty-two week highs (lows). Kaustia (2004) uses the price and volume information on US initial public offerings (IPOs) to find that for negative 
initial return IPOs, trading below the offer price (which is assumed to be the reference point) is suppressed in comparison to trading above the offer price, and that there is an increase in trading volume as their stock prices reach new record highs.

The second major group of papers studying the disposition effect is based on individual data. The reference point in these studies is taken to be the stocks' purchase prices. In a comprehensive research, Odean (1998) takes the average purchase price (for each investor and stock) as a reference point and then distinguishes between paper, vs. realized, gains and losses. For each day and investor, he calculates the Proportion of Gains Realized (PGR) and the Proportion of Losses Realized (PLR), taking the ratio of PGR to PLR as a measure of the disposition effect. Odean's main findings include the observation that individual investors demonstrate significant preferences for selling winners and holding losers. Dhar and Zhu (2002) find that the disposition effect is mainly pronounced by low-income and non-professional investors. Goetzmann and Massa (2003) argue that investors' disposition bias affects the firms' returns. Grinblatt and Han (2005) were the first to connect the disposition effect and momentum, showing, both theoretically and empirically, that the disposition effect may account for the tendency of past winning stocks to subsequently outperform past losing stocks. Frazzini (2006) finds that in the presence of disposition-prone investors, prices under-react to news, generating thereby a post-event price drift. Locke and Mann (2005) find that the average holding period for losing trades is longer than for winning trades. They argue that, while all traders hold losers longer than winners, the least successful traders hold losers the longest, while the most successful traders hold losers for the shortest time. Shapira and Venezia (2000) compare the duration of winning and losing round trips and document the disposition effect for all groups of accounts, finding that it is less pronounced for managed, than for independent, accounts. Kliger and Kudryavtsev (2008) discover that investors update their reference points on stocks following stock exchange-listed firms' quarterly earnings announcements perceived as "good" or "bad surprises", and subsequently exhibit disposition effect with respect to these reference points.

The third group of papers that sheds light on the disposition effect consists of papers employing experimental design. Weber and Camerer (1998) carry a multi-stage experiment examining different characteristics and determinants of the disposition effect and find that subjects tend to sell fewer shares when the price falls than when it rises and also sell less when the price is below the purchase price than when it is above. Similarly to Weber and Camerer (1998), Oehler et al. (2002) use the purchase price and the last period price as alternative reference points. The disposition effect is found to be stronger when the purchase price is taken as a reference point.

\subsection{Herd Behavior (Herding)}

In financial markets, herding is usually termed as the behavior of an investor imitating the observed actions of others or the movements of market instead of following her own beliefs and information. Possibly herd behavior is among the most mentioned but least understood terms in the financial lexicon. Difficulties to measure and quantify the existence of the behavior form obstacles for extensive research. Even so, there are at least two points people tend to unanimously agree upon. First, as one of the founding pillars in newly developed behavioral asset pricing area, herd behavior helps to explain market wide anomalies. Since individual biases are not influential enough to move market prices and returns, they have real anomalous effect only if there is a social contamination with a strong emotional content, leading to more widespread phenomena such as herd behavior. Second, it is generally accepted that the flood of herding may lead to a situation in which the market price fails to reflect all relevant information and thus the market becomes unstable and moves towards inefficiency.

Theoretical and empirical research of herd behavior has been conducted in an isolated manner. The theoretical work (e.g., Avery and Zemsky (1998), Lee (1998), Cipriani and Guarino (2008), Park and Sabourian (2010)) tries to identify the mechanisms that can lead traders to herd. Papers in this literature emphasize that in financial markets, the fact that prices adjust to the order flow makes herd behavior more difficult to arise than in other setups, studied in the social learning literature, where there is no price mechanism. Nevertheless, it is possible that rational traders herd, because there are different sources of uncertainty in the market, because traders have informational and non-informational (e.g., liquidity or hedging) motives to trade or because trading activity is affected by reputation concerns.

Empirical studies of herd behavior employ either laboratory or market data. In all the models, "herding" means making the same decision independently of the private information that one receives. The problem for the empiricist is that there are no data on the private information available to the traders and, therefore, it is difficult to understand whether traders make similar decisions because they disregard their own information and imitate (as opposed, for instance, to reacting to the same piece of public information). To overcome this problem, some authors (e.g., Cipriani and Guarino, (2005, 2009), Drehman et al. (2005)) test herd behavior in laboratory financial markets, and document types of behavior consistent with herd motives. 
A series of empirical studies make an effort to detect and measure herd behavior in real market situations. Lakonishok et al. (1992) measure herd behavior as the average tendency of a group of money managers to buy or sell particular stocks at the same time, relative to what could be expected if the managers make their decision independently. Wermers (1995) proposes a portfolio-change measure, by which herd behavior is measured by the extent to which portfolio weights assigned to the various stocks by different money managers move in the same direction. Christie and Huang (1995) document lower volatility of individual security returns in the periods of extremely positive and extremely negative market returns, which is in line with herding behavior and contradicts rational asset pricing. Hwang and Salmon (2004) and Wang and Canela (2006) employ cross-sectional variance of the betas to study herd behavior towards market index in major developed and emerging financial markets. They find a higher level of herding in emerging markets than in developed markets, and higher correlations of herding between two markets from the same group compared to those between two markets from different groups. They also argue that herd behavior shows significant movements and persistence independently from market conditions.

\subsection{Availability Heuristic}

The availability heuristic (Tversky and Kahneman (1973)) refers to the phenomenon of determining the likelihood of an event according to the easiness of recalling similar instances. In other words, the availability heuristic may be described as a rule of thumb, which occurs when people estimate the probability of an outcome based on how easy that outcome is to imagine. As such, vividly described, emotionally-charged possibilities will be perceived as being more likely than those that are harder to picture or difficult to understand. Tversky and Kahneman (1974), provide examples of ways availability may provide practical clues for assessing frequencies and probabilities. They argue that "recent occurrences are likely to be relatively more available than earlier experiences" (p. 1127), and, thus, conclude that people assess probabilities by overweighting current information, as opposed to processing all relevant information.

A number of papers discuss the influence of the availability heuristic on market investors. Shiller (1998) argues that investors' attention to investment categories (e.g., stocks versus bonds or real estate; investing abroad versus investing at home) may be affected by alternating waves of public attention or inattention. Similarly, Barber and Odean (2008) find that when choosing which stock to buy, investors tend to consider only those stocks that have recently caught their attention (stocks in the news, stocks experiencing high abnormal trading volume, stocks with extreme one day returns). Daniel et al. (2002) conclude that investors and analysts are on average too credulous, that is, when examining an informative event or a value indicator, they do not discount adequately for the incentives of others to manipulate this signal. Credulity may be explained by limited attention and the fact that availability of a stimulus causes it to be weighed more heavily. Frieder (2003) finds that stock traders seek to buy after large positive earnings surprises and sell after large negative earnings surprises, and explains this tendency by the availability heuristic, assuming that the salience of an earnings surprise increases in its magnitude. Ganzach (2001) brings support for a model in which analysts base their judgments of risk and return for unfamiliar stocks upon a global attitude. If stocks are perceived as good, they are judged to have high return and low risk, whereas if they are perceived as bad, they are judged to be low in return and high in risk. Lee et al. (2007) discuss the "recency bias", which is the tendency of people to make judgments about the likelihood of events based on their recent experience. They find that analysts' forecasts of firms' long-term growth in earnings per share tend to be relatively optimistic when the economy is expanding and relatively pessimistic when the economy is contracting. This finding is consistent with the availability heuristic, indicating that forecasters overweight current state of the economy in making long-term growth predictions. Kliger and Kudryavtsev (2010) find that positive stock price reactions to analyst recommendation upgrades are stronger when accompanied by positive stock market index returns, and negative stock price reactions to analyst recommendation downgrades are stronger when accompanied by negative stock market index returns. They dub this finding "outcome availability effect" and explain it by higher availability of positive (negative) outcomes on days of market index rises (declines). Moreover, Kliger and Kudryavtsev (2010) document weaker (stronger) reactions to recommendation upgrades (downgrades) on days of substantial stock market moves. They dub this finding "risk availability effect" and explain it by higher availability of risky outcomes on such "highly volatile" days.

\subsection{Gambler's Fallacy}

The gambler's fallacy is defined as an (incorrect) belief in negative autocorrelation of a non-autocorrelated random sequence. For example, individuals who believe in the gambler's fallacy believe that after three red numbers appearing on the roulette wheel, a black number is "due," that is, is more likely to appear than a red number.

The first published account of the gambler's fallacy is from Laplace (1796). Gambler's fallacy-type beliefs are first observed in the laboratory (under controlled conditions) in the literature on probability matching. In these 
experiments subjects are asked to guess which of two colored lights would next illuminate. After seeing a string of one outcome, subjects are significantly more likely to guess the other, an effect referred to in that literature as negative recency (see Estes, 1964, and Lee, 1971, for reviews). Ayton and Fischer (2004) also demonstrate the existence of gambler's fallacy beliefs in the lab when subjects choose which of two colors will appear next on a simulated roulette wheel. Gal and Baron (1996) show that gambler's fallacy behavior is not simply caused by boredom. They ask participants in their experiments how they would best maximize their earnings, and get responses based on gambler's fallacy type logic.

The gambler's fallacy is thought to be caused by the representativeness heuristic (Tversky and Kahneman (1971), Kahneman and Tversky (1972)). Here, chance is perceived as "a self-correcting process in which a deviation in one direction induces a deviation in the opposite direction to restore the equilibrium" (Tversky and Kahneman (1974), p. 1125). Thus after a sequence of three red numbers appearing on the roulette wheel, black is more likely to occur than red because a sequence "red-red-red-black" is more representative of the underlying distribution than a sequence "red-red-red-red".

A number of researchers demonstrate the existence of the gambler's fallacy empirically, in lottery and horse or dog racing settings. For example, Clotfelter and Cook $(1991,1993)$ and Terrell (1994) show that soon after a lottery number wins, individuals are significantly less likely to bet on it. This effect diminishes over time; months later the winning number is as popular as the average number. Metzger (1984), Terrell and Farmer (1996) and Terrell (1998) show the gambler's fallacy in horse and dog racing. Croson and Sundali (2005) and Sundali and Croson (2006) use videotapes of play of a roulette table in casino and document a significant gambler's fallacy in betting. That is, following a sequence of one color outcomes, people are more likely to place their bets on the other color.

Zielonka (2004) asks a group of stock market professionals a number of questions aimed at detecting their way of making decisions, and documents that market "signals" considered by technical analysts are consistent with a number of behavioral biases, including gambler's fallacy.

Overall, the gambler's fallacy is well-documented both in the laboratory and in the real-world, including money-related behavior. Yet, on the other hand, there seems to be little evidence of this pattern in financial, including stock market decision-making.

\subsection{Hot Hand Fallacy}

In the same time when people exhibit the gambler's fallacy, which is a tendency to predict the opposite of the last event (negative recency), they also express beliefs that certain events will be repeated (positive recency). The latter tendency is known as hot hand fallacy, and unlike gambler's fallacy it refers to people's belief that a particular person, rater than outcome is hot. For example, if an individual has won in the past, whatever numbers she chooses to bet on are likely to win in the future, not just the numbers she has won with previously.

Gilovich, Vallone and Tversky (1985) are the first to dub the term of "hot hand". They demonstrate that individuals believe in the hot hand in basketball shooting, and that these beliefs are not correct (i.e., basketball shooters' probability of success is serially uncorrelated). They suggest that the hot hand also arises out of the representativeness heuristic, just as the gambler's fallacy. They write: "A conception of chance based on representativeness produces two related biases. First, it induces a belief that the probability of heads is greater after a long sequence of tails than after a long sequence of heads - this is the notorious gambler's fallacy. Second, it leads people to reject the randomness of sequences that contain the expected number of runs because even the occurrence of, say, four heads in a row - which is quite likely in a sequence of 20 tosses - makes the sequence appear non-representative". Another potential explanation for the hot hand fallacy may be related to Langer (1975) dealing with the illusion of control, that is, people's tendency to believe that they (or others) exert control over events that are in fact randomly determined.

Other experimental evidence shows that subjects in a simulated blackjack game bet more after a series of wins than they do after a series of losses, both when betting on their own play and on the play of others (Chau and Phillips (1995)). Further evidence of the hot hand in a laboratory experiment comes from Ayton and Fischer (2004) who document both the gambler's fallacy and the hot hand fallacy and conclude that the former is attributed to "randomly looking" processes and to inanimate chance mechanisms, while the latter refers to processes that seem to be non-random and to human skilled performance.

The evidence for the hot hand from the field is weaker. Camerer (1989) compares odds in the betting market for basketball teams with their actual performance and finds that bettors do appear to believe in the "hot team". Croson and Sundali (2005) and Sundali and Croson (2006) document hot hand consistent behavior in casino. Clotfelter and Cook (1989) note the tendency of gamblers to redeem winning lottery tickets for more tickets rather than for cash. 
This behavior is also consistent with hot hand beliefs, since the individuals who have recently won seem to believe they are more likely to win again.

Overall, similarly to the gambler's fallacy, the hot fallacy is widely discussed by different branches of literature, but is not sufficiently documented in financial research, possibly, because it is quite difficult to establish the hot hand feelings particular investors may have at certain moments of time.

In present study, we first of all, wish to shed a little more light on the effects of the above-discussed psychological patterns on financial decision-making. This may be especially valuable for the case of the gambler's fallacy and the hot hand fallacy, whose potential effects on the field of finance are not sufficiently studied by previous literature. Yet, the major goal of this study is to analyze the individual differences in the magnitudes of these biases, the matter which is almost not discussed in previous financial literature.

\section{Survey Design and Research Approach}

We gathered the data for this study in the framework of a computerized survey, consisting of two stages:

First, we asked a group of professional portfolio managers (41 managers) at one of the major Israeli investment houses to fill in a short questionnaire.

Second, we conducted online survey via one of the leading financial web-sites in Israel. The web-site we used is widely recognized for being regularly visited by market investors, not necessarily professional. We got responses from 305 users (Note 1).

We asked all the respondents to indicate their gender, age, and number of years of active experience in the capital market. Table 1 (in Appendix 1) reports the basic descriptive statistics of our sample. The majority of our participants were males (78.05\% and $74.10 \%$ in the professionals and non-professionals groups, respectively), 30 to 40 years old $(53.66 \%$ and $55.08 \%$, respectively), and had more than 10 years of experience in stock market investments (39.02\% and $40.98 \%$, respectively).

Our survey questionnaire consisted of 10 questions, which are presented in Appendix. In each question, participants were asked to rate appropriateness of a statement on a Likert scale between 1 (strongly disagree) and 5 (strongly agree).

The goal of the questionnaire was to detect if stock market investors were affected by different psychological biases. In this respect, the statements were formulated so that questions 1 and 2 referred to the disposition effect, questions 3 and 4 to the gambler's fallacy, questions 5 and 6 to the hot hand fallacy, questions 7 and 8 to the herd behavior, and questions 9 and 10 to the availability heuristic. According to the definition of the biases and the formulation of the questions, for all our questions, except question 2, a higher grade provided by a participant would be consistent with a stronger effect of the respective bias on her.

In order to capture the effect of each of the behavioral biases on each of our participants, we calculate their personal "bias grades". To do so, we first of all, control for the cross-sectional correlations of grades given by the participants within the "pairs" of the questions we employ for each of the biases.

The correlation coefficients between the grades within the pairs are reported in Table 2. The Table clearly demonstrates that the correlations within all the pairs are highly significant for both groups of participants. We also note that the sign of the correlation between the grades on questions 1 and 2 is negative, which is due to the fact that investment behavior consistent with the disposition effect would require a high grade on question 1 and a low grade on question 2 .

Strong correlations within the pairs of questions allow us to aggregate the bias grades for each participant $\mathrm{i}$ and for each of the biases, in the following way:

Disposition grade $\left(D G_{i}\right)$ :

$$
D G_{i}=G_{-} 1_{i}+6-G_{-} 2_{i}
$$

(Note 2)

where: $G_{-} N_{i}$ is the grade (answer) given by participant i for question (statement) $\mathrm{N}$.

Gambler's grade $\left(G G_{i}\right)$ :

$$
G G_{i}=G_{-} 2_{i}+G_{-} 3_{i}
$$

Hot-hand grade $\left(H G_{i}\right)$ : 


$$
H G_{i}=G_{-} 5_{i}+G_{-} 6_{i}
$$

Herd (behavior) grade $\left(B G_{i}\right)$ :

$$
B G_{i}=G_{-} 7_{i}+G_{-} 8_{i}
$$

Availability grade $\left(A G_{i}\right)$ :

$$
A G_{i}=G_{-} 9_{i}+G_{-} 10_{i}
$$

\section{Testable Hypotheses and Results}

First of all, we look at the general picture of the bias grades in our sample. Table 3 concentrates descriptive statistics in this respect, and shows some general results:

All the bias grades for both groups range from 2 (minimal possible grade) to 9-10 (maximal possible grade). In other words, in our sample, we have both participants who seem to be fully affected and completely unaffected by the respective behavioral patterns.

The mean bias grades range from 4.927 to 5.646, and the majority of the participants have bias grades lower than 6 . We, therefore, may infer that our participants are, on average, moderately affected by behavioral biases.

Yet, the major goal of our paper is to analyze the individual differences in the bias grades, and we now proceed to this analysis.

\subsection{Behavioral Biases and Investors' Trading Experience}

Trading experience seems to be the most reasonable "candidate" for a factor eliminating (or at least, diminishing) behavioral biases. One might expect stock market investors to behave more rationally the more knowledge about the market they have accumulated. Still, previous evidence on the effect of experience on the magnitude of various behavioral biases is rather scarce. In an experimental setting, List (2003) finds that market experience plays a significant role in eliminating the endowment effect (Note 3). List further suggests that market experience is likely to diminish other "market anomalies", as well, yet, does not provide such evidence. Dhar and Zhu (2002), in addition to other findings, demonstrate that the disposition effect is mainly pronounced by non-professional investors.

We make an effort to fill this certain gap in literature dealing with behavioral economics and finance. Our sample allows us to analyze the magnitudes of the biases by two different proxies for investors' experience:

Investors' level of "professionalism",

Number of years of stock trading experience.

In this respect, we hypothesize two things:

Hypothesis 1a: All the behavioral effects are more strongly pronounced for non-professional investors.

and

Hypothesis 1b: All the behavioral effects are more strongly pronounced for less experienced investors.

In order to test Hypothesis 1a, for each of the five behavioral patterns, we compare the mean bias grades between the two groups of participants: (i) professional portfolio managers, and (ii) visitors of financial web-site (not necessarily professional).

Table 4 presents the mean comparison tests. Indeed, in line with Hypothesis 1a, mean bias grades for all the five behavioral patterns, are higher for the participants who answered via the web-site. Yet, all the differences are non-significant, which does not allow us to support the Hypothesis. In other words, we may infer that the "status" of being a professional does not by itself make stock market investors less affected by behavioral biases.

Furthermore, we test Hypothesis $1 \mathrm{~b}$. We compare the mean bias grades between the categories of participants according to their reported investment experience. Since the subsample of professional investors is relatively small, we employ only the subsample of web-site visitors for this analysis. Table 5 comprises the comparative statistics for adjacent categories of reported market experience: (i) "Less than 3 years" versus "3 to 5 years"; (ii) "3 to 5 years" versus " 5 to 10 years"; and (iii) "5 to 10 years" versus "More than 10 years". The results strongly support Hypothesis 1b. For all the five behavioral effects, the longer is the reported investment experience the lower are the mean bias grades. All the differences (15) between the mean bias grades for the adjacent categories are significantly greater than zero (11 of them at the $1 \%$ level) (Note 4). That is, unlike investors' "professionalism", their experience in stock market investments does decrease the effect of behavioral biases on them. An additional thing we may observe from 
Table 5 is that for all the behavioral effects, the differences themselves between the mean bias grades decrease with investors' experience (i.e., the difference between categories 1 and 2 is greater than the difference between categories 2 and 3, which in its turn, is greater than the difference between categories 3 and 4). So, it seems that investors always learn from experience and behave more and more rationally, yet, the major "rationalizing" effect of experience is already accumulated in the first years of active investment.

Finally, in order to amplify the findings of this Subsection, we directly confront the effect of investors' "professionalism" on their behavior with the respective effect of investors' experience. We compare the mean bias grades between the subsample of professional portfolio managers and the category of the most experienced investors (reporting market experience of more than 10 years) from the subsample of non-professional investors. Table 6 comprises the results and demonstrates that all the five differences are highly significant. That is, investors' experience has a definitely stronger "rationalizing" effect on their way of decision-making than the "status" itself of being a professional.

\subsection{Behavioral Biases by Investors' Gender}

Men and women are different, and their behavior may be different in many ways. Women (on average) are universally recognized to rely on their intuition and to be driven by feelings and emotions, while men (again, on average) are thought to rely on logic. Previous psychological literature concludes that men are more assertive and independent in their thoughts and actions, while women are more willing to follow the ideas suggested by others (Feingold (1994), Helgeson (1994, 2003), Fritz and Helgeson (1998)). In the same spirit, Cross and Madson (1997) argue that women are more likely than men to develop an interdependent or relational self-construal, reflecting the importance of social connections and relationships, whereas men are more likely than women to develop an independent or agentic self-construal, reflecting a concern for social dominance and assertiveness (see also, Gabriel and Gardner (1999), Hyde (2005)).

Therefore, one might expect female investors to be more affected by various "intuitive" behavioral patterns, than male investors. In line with this suggestion, Kudryavtsev and Cohen (2011) find that women exhibit stronger hindsight bias (Note 5) and anchoring bias (Note 6) in recalling recent stock market outcomes. Yet, to our best knowledge, there are no studies analyzing gender differences with respect to the effects of the five behavioral biases we are dealing with on economic and financial decision-making. We wish to fill this gap, and in accordance with the discussion above, hypothesize that:

Hypothesis 2: All the behavioral effects in financial decision-making are more strongly pronounced for female investors.

To test Hypothesis 2, we employ the same approach as in the previous Subsection. Table 7 reports, for each of the five behavioral effects, the mean bias grades for men and women and the test statistics for the respective differences. The results clearly support Hypothesis 2, indicating that for all the biases, the mean bias grades are significantly (at the $1 \%$ level) higher for women than for men. That is, as expected, female investors are more likely to employ simplifying rules of decision-making.

\section{Conclusions and Discussion}

Our paper explores the effects of behavioral biases, namely, disposition effect, herd behavior, availability heuristic, gambler's fallacy and hot hand fallacy, on the mechanism of stock market decision-making, and, in particular, the individual differences in the degrees of these effects.

Employing an extensive online survey, we document that on average, active stock market investors exhibit moderate degrees of behavioral biases. Furthermore, we find that, on the one hand, more experienced investors are less affected by behavioral patterns, yet, on the other hand, professional portfolio managers do not behave, in this respect, differently (more rationally) from non-professional investors. Moreover, professional investors appear to be significantly stronger influenced by the behavioral effects, than non-professional but experienced investors. In addition, we detect that the major "rationalizing" effect of experience is already accumulated in the first years of investors' stock market activity. Finally, we document that female investors are more strongly affected by all the five behavioral biases.

Our results may have a number of interesting implications. First of all, in what concerns the rationality of stock market investment decisions, the time, as always, is the best healer. On the other hand, the "professionalism" of the portfolio managers, when viewed apart of the effect of experience, does not appear to change their way of decision-making. This finding may serve a useful food for thought for the financial companies' managers.

In addition, in line with previous psychological literature, we document that female investors are more likely to rely on some simple and "intuitive" rules and techniques of decision-making. It follows that stock market analysts and all 
other potentially interested persons should probably find it easier to manipulate female investors' views, opinions and decisions with respect to some particular financial assets and the stock market, in general. Both "sides of the game" might pay attention to this finding.

\section{References}

Avery, C., \& Zemsky, P. (1998). Multidimensional Uncertainty and Herd Behavior in Financial Markets. American Economic Review, 88(4), 724-48.

Ayton, P. \& Fischer, I. (2004). The Hot Hand Fallacy and the Gambler's Fallacy: Two Faces of Subjective Randomness? Memory and Cognition, 32, 1369-1378. http://dx.doi.org/10.3758/BF03206327.

Barber, B. M., \& Odean, T. (2008). All that Glitters: The Effect of Attention and News on the Buying behavior of Individual and Institutional Investors. Review of Financial Studies, 21(2), 785-818.

Bremer, M., \& Kato K. (1996). Trading Volume for Winners and Losers on the Tokyo Stock Exchange, Journal of Financial and Quantitative Analysis, 31(1), 127-142. http://dx.doi.org/10.2307/2331390.

Camerer, C. (1989). Does the Basketball Market Believe in the 'Hot Hand'? American Economic Review, 79(5), $1257-1261$.

Chau, A., \& Phillips, J. (1995). Effects of Perceived Control upon Wagering and Attributions in Computer Blackjack. The Journal of General Psychology, 122(3), 253-269. http://dx.doi.org/10.1080/00221309.1995.9921237.

Christie, W. G., \& Huang, R. D. (1995). Following the Pied Piper: Do Individual Returns Herd Around the Market? Financial Analysts Journal, 51(4), 31-37. http://dx.doi.org/10.2469/faj.v51.n4.1918.

Cipriani, M., \& Guarino, A. (2005). Herd Behavior in a Laboratory Financial Market. American Economic Review, 95(5), 1427-1443. http://dx.doi.org/10.1257/000282805775014443.

Cipriani, M., \& Guarino, A. (2008). Herd Behavior and Contagion in Financial Markets. The B.E. Journal of Theoretical Economics (Contributions), 8, Art. 24. http://dx.doi.org/10.2202/1935-1704.1390.

Cipriani, M., \& Guarino, A. (2009). Herd Behavior in Financial Markets: A Field Experiment with Financial Market Professionals. Journal of the European Economic Association, 7(1), 206-233.

Clotfelter, C., \& Cook, P. (1989). Selling Hope: State Lotteries in America. Cambridge: Harvard University Press.

Clotfelter, C., \& Cook, P. (1991). Lotteries in the Real World. Journal of Risk and Uncertainty, 4(3), 227-232. http://dx.doi.org/10.1007/BF00114154.

Clotfelter, C., \& Cook, P. (1993). The 'Gambler's Fallacy' in Lottery Play. Management Science, 39(12), $1521-1525$.

Croson, R., \& Sundali, J. (2005). The Gambler's Fallacy and the Hot Hand: Empirical Data from Casinos. Journal of Risk and Uncertainty, 30(3), 195-209. http://dx.doi.org/10.1007/s11166-005-1153-2.

Cross, S. E., \& Madson, L. (1997). Models of the Self: Self-Construals and Gender, Psychological Bulletin, 122, 5-137. http://dx.doi.org/10.1037//0033-2909.122.1.5.

Daniel, K., Hirshleifer, D., \& Teoh, S. H. (2002). Investor Psychology in Capital Markets: Evidence and Policy Implications. Journal of Monetary Economics, 49(1), 139-209. http://dx.doi.org/10.1016/S0304-3932(01)00091-5.

Dhar, R., \& Zhu, N. (2002). Up Close and Personal: An Individual Level Analysis of the Disposition Effect. Working Paper, Yale School of Management. http://dx.doi.org/10.2139/ssrn.302245.

Drehmann, M., Oechssler, J., \& Rider, A. (2005). Herding and Contrarian Behavior in Financial Markets - An Internet Experiment. American Economic Review, 95(5), 1403-1426. http://dx.doi.org/10.1257/000282805775014317.

Estes, W. (1964). Probability Learning. In A.W. Melton (ed.), Categories of Human Learning, New York: Academic Press.

Feingold, A. (1994). Gender Differences in Personality: A Meta-Analysis. Psychological Bulletin, 116(3), 429-456. http://dx.doi.org/10.1037//0033-2909.116.3.429.

Ferris, S., Haugen, R.A., \& Makhija, A.K. (1988). Predicting Contemporary Volume with Historic Volume at Differential Price Levels: Evidence Supporting the Disposition Effect. Journal of Finance, 43, 677-697. http://dx.doi.org/10.1111/j.1540-6288.1987.tb01179.x.

Frazzini, A. (2006). The Disposition Effect and Under-Reaction to News. Journal of Finance, 61(4), 2017-2046. 
Frieder, L. (2003). Evidence on Behavioral Biases in Trading Activity. Working Paper, UCLA, The Anderson School. http://dx.doi.org/10.2139/ssrn.479983.

Fritz, H. L., \& Helgeson, V. S. (1998). Distinctions of Unmitigated Communion from Communion: Self-Neglect and Over-Involvement with Others. Journal of Personality and Social Psychology, 75, 121-140.

Gabriel, S., \& Gardner, W. L. (1999). Are There 'His' and 'Hers' Types of Interdependence? The Implications of Gender Differences in Collective versus Relational Interdependence for Affect, Behavior, and Cognition. Journal of Personality and Social Psychology, 77, 642-655.

Gal, I., \& Baron, J. (1996). Understanding Repeated Simple Choices. Thinking and Reasoning, 2, 81-98. http://dx.doi.org/10.1080/135467896394573.

Ganzach, Y. (2001). Judging Risk and Return of Financial Assets. Organizational Behavior and Human Decision Processes, 83, 353-370. http://dx.doi.org/10.1006/obhd.2000.2914.

Gilovich, T., Vallone, R., \& Tversky, A. (1985). The Hot Hand in Basketball: On the Misperception of Random Sequences. Cognitive Psychology, 17, 295-314. http://dx.doi.org/10.1016/0010-0285(85)90010-6.

Goetzmann, W. N., \& Massa, M. (2003). Disposition Matters: Volume, Volatility and Price Impact of a Behavioral Bias. Working Paper, Yale School of Management.

Grinblatt, M., \& Han, B. (2005). Prospect Theory, Mental Accounting and Momentum. Journal of Financial Economics, 78(2), 311-339. http://dx.doi.org/10.1016/j.jfineco.2004.10.006.

Helgeson, V. S. (1994). Relation of Agency and Communion to Well-Being: Evidence and Potential Explanations. Psychological Bulletin, 116(3), 412-428. http://dx.doi.org/10.1037//0033-2909.116.3.412.

Helgeson, V. S. (2003). Unmitigated Communion and Adjustment to Breast Cancer: Associations and Explanations. Journal of Applied Social Psychology, 33, 1643-1661.

Hirshleifer D., \& Teoh, S. H. (2003). Herd Behavior and Cascading in Capital Markets: A Review and Synthesis. European Financial Management, 9(1), 25-66. http://dx.doi.org/10.2139/ssrn.296081.

Huddart, S., Lang, M., \& Yetman, M. (2007). Psychological Factors, Stock Price Paths, and Trading Volume. Working Paper, Pennsylvania State University. http://dx.doi.org/10.2139/ssrn.353749.

Hwang, S., \& Salmon, M. (2004). Market Stress and Herding. Journal of Empirical Finance, 11, 585-616. http://dx.doi.org/10.1016/j.jempfin.2004.04.003.

Hyde, J. S. (2005). The Gender Similarities Hypothesis. American Psychologist, 60(6), 581-592. http://dx.doi.org/10.1037/0003-066X.60.6.581.

Kahneman, D., \& Tversky, A. (1972). Subjective Probability: A Judgment of Representativeness. Cognitive Psychology, 3, 430-454. http://dx.doi.org/10.1016/0010-0285(72)90016-3.

Kahneman, D., \& Tversky, A. (1979). Prospect Theory: An Analysis of Decision under Risk. Econometrica, 46(2), 171-185. http://dx.doi.org/10.2307/1914185.

Kahneman, D., Slovic, P., \& Tversky, A. (1982). Judgment under Uncertainty: Heuristics and Biases. New York: Cambridge University Press.

Kaustia, M. (2004). Market-Wide Impact of the Disposition Effect: Evidence from IPO Trading Volume. Journal of Financial Markets, 7(2), 207-235. http://dx.doi.org/10.1016/j.finmar.2003.11.002.

Kliger, D., \& Kudryavtsev, A. (2008). Reference Point Formation by Market Investors. Journal of Banking and Finance, 32(9), 1782-1794. http://dx.doi.org/10.1016/j.jbankfin.2007.12.006.

Kliger, D., \& Kudryavtsev, A. (2010). The Availability Heuristic and Investors' Reaction to Company-Specific Events. Journal of Behavioral Finance, 11(1), 50-65.

Kudryavtsev, A., \& Cohen, G. (2011). Behavioral Biases in Economic and Financial Knowledge: Are They the Same for Men and Women? Advances in Management and Applied Economics, 1(1), 15-52.

Lakonishok, J. Shleifer, A., \& Vishny, R. W. (1992). The Impact of Institutional Trading on Stock Prices. Journal of Financial Economics, 32(1), 23-43. http://dx.doi.org/10.1016/0304-405X(92)90023-Q.

Lakonishok, J., \& Smidt, S. (1986). Volume for Winners and Losers: Taxation and Other Motives for Stock Trading. Journal of Finance, 41(4), 951-974. http://dx.doi.org/10.2307/2328239.

Langer, E. (1975). The Illusion of Control. Journal of Personality and Social Psychology, 32(2), 311-328. http://dx.doi.org/10.1037//0022-3514.32.2.311 
Laplace, P. S. (1951). A Philosophical Essay on Probabilities. New York: Dover (Original work published in 1796).

Lee, B, O'Brien, J., \& Sivaramakrishnan, K. (2007). An Analysis of Financial Analysts' Optimism in Long-term Growth Forecasts. Journal of Behavioral Finance, 9(3), 171-184.

Lee, I. H. (1998). Market Crashes and Informational Avalanches. Review of Economic Studies, 65, 741-759. http://dx.doi.org/10.1111/1467-937X.00066.

Lee, W. (1971). Decision Theory and Human Behavior. New York: Wiley.

List, J. A. (2003). Does Market Experience Eliminate Market Anomalies. Quarterly Journal of Economics, 118(1), 41-71. http://dx.doi.org/10.1162/00335530360535144.

Locke, P. R., \& Mann, S. C. (2005). Professional Trader Discipline and Trade Disposition. Journal of Financial Economics, 76(2), 401-444. http://dx.doi.org/10.1016/j.jfineco.2004.01.004.

Metzger, M. (1984). Biases in Betting: An Application of Laboratory Findings. Psychological Reports, 56(3), 883-888. http://dx.doi.org/10.1142/9789812819192.

Odean, T. (1998). Are Investors Reluctant to Realize Their Losses? Journal of Finance, 53(5), 1775-1798. http://dx.doi.org/10.1111/0022-1082.00072.

Oehler, A., Heilmann, K., Lager, V., \& Oberlander, M. (2002). Dying Out or Dying Hard? Disposition Investors in Stock Markets. Working Paper, Bamberg University. http://dx.doi.org/10.2139/ssrn.314139.

Park, A., \& Sabourian, H. (2010). Herd Behavior in Efficient Financial Markets. Working Paper, Cambridge University.

Shapira, Z., \& Venezia, I. (2001). Patterns of Behavior of Professionally Managed and Independent Investors. Journal of Banking and Finance, 25(8), 1573-1587. http://dx.doi.org/10.1016/S0378-4266(00)00139-4.

Shefrin, H., \& Statman, M. (1985). The Disposition to Sell Winners Too Early and Ride Losers Too Long. Journal of Finance, 40(3), 777-790. http://dx.doi.org/10.2307/2327802.

Shiller, R. J. (1998). Human Behavior and the Efficiency of the Financial System. NBER Working Paper. http://dx.doi.org/10.1016/S1574-0048(99)10033-8.

Stracca, L. (2004). Behavioral Finance and Asset Prices: Where Do We Stand? Journal of Economic Psychology, 25(3), 373-405. http://dx.doi.org/10.1016/S0167-4870(03)00055-2.

Sundali, J., \& Croson, R. (2006). Biases in Casino Betting: The Hot Hand and the Gambler's Fallacy. Judgment and Decision Making, 1(1), 1-12.

Terrell, D. (1994). A Test of the Gambler's Fallacy: Evidence from Pari-Mutuel Games. Journal of Risk and Uncertainty, 8(3), 309-317. http://dx.doi.org/10.1007/BF01064047.

Terrell, D. (1998). Biases in Assessments of Probabilities: New Evidence from Greyhound Races. Journal of Risk and Uncertainty, 17(2), 151-166.

Terrell, D., \& Farmer, A. (1996). Optimal Betting and Efficiency in Parimutuel Betting Markets with Information Costs. The Economic Journal, 106(437), 846-868. http://dx.doi.org/10.2307/2235361.

Thaler, R. (1985). Mental Accounting and Consumer Choice. Marketing Science, 4(3), 199-214. http://dx.doi.org/10.1287/mksc.1070.0330.

Tversky, A., \& Kahneman, D. (1971). Belief in the Law of Small Numbers. Psychological Bulletin, 76(2), 105-110. http://dx.doi.org/10.1037/h0031322.

Tversky, A., \& Kahneman, D. (1973). Availability: A Heuristic for Judging Frequency and Probability. Cognitive Psychology, 5(2), 207-232. http://dx.doi.org/10.1016/0010-0285(73)90033-9.

Tversky, A., \& Kahneman, D. (1974). Judgment under Uncertainty: Heuristics and Biases. Science, 185(4157), 1124-1131. http://dx.doi.org/10.1126/science.185.4157.1124.

Wang, D., \& Canela, M. (2006). Herd Behavior towards the Market Index: Evidence from 21 Financial Markets. Working Paper, University of Barcelona.

Weber, M., \& Camerer, C. F. (1998). The Disposition Effect in Securities Trading: An Experimental Analysis. Journal of Economic Behavior and Organization, 33(2), 167-184. http://dx.doi.org/10.1016/S0167-2681(97)00089-9.

Wermers, R. (1995). Herding, Trade Reversals, and Cascading by Institutional Investors. Working Paper, University of Colorado. 
Zielonka, P. (2004). Technical Analysis as the Representation of Typical Cognitive Biases. International Review of Financial Analysis, 13(2), 217-225. http://dx.doi.org/10.1016/j.irfa.2004.02.007.

\section{Notes}

Note 1. The first stage of the survey took place in January 2011, and the second one in March-April 2011. The "Bizportal" (http://www.bizportal.co.il/) web-site was involved.

Note 2. We subtract the grade on question 2, since it is negatively correlated with the magnitude of the disposition effect exhibited by the respective participants. The number " 6 " is added in order to reduce the disposition grade to the same "2-to-10" scale as the rest of the bias grades.

Note 3. Endowment effect is a tendency of people to demand more compensation to give up an object than they would be willing to pay for it.

Note 4. Of course, all the differences between the categories 1 and 3, 2 and 4, and 1and 4 are significantly greater than zero at the $1 \%$ level.

Note 5. Hindsight bias denotes people's tendency to overestimate, in hindsight, how predictable an outcome was in foresight.

Note 6. Anchoring bias refers to people's tendency to form their estimates for different categories, starting from a particular available, and often irrelevant, value and insufficiently adjusting their final judgments from this starting value.

Table 1. Sample descriptive statistics

\begin{tabular}{|c|c|c|}
\hline \multicolumn{3}{|c|}{ Panel A: Portfolio managers (41 respondents) } \\
\hline Category & Number & Percent of total \\
\hline 1. Gender: & & \\
\hline Men & 32 & 78.05 \\
\hline Women & 9 & 21.95 \\
\hline 2. Age: & & \\
\hline $18-30$ & 9 & 21.95 \\
\hline $30-40$ & 22 & 53.66 \\
\hline $40-50$ & 9 & 21.95 \\
\hline $50-60$ & 1 & 2.44 \\
\hline $60+$ & 0 & 0.00 \\
\hline 3. Capital market investor for: & & \\
\hline Less than 3 years & 5 & 12.20 \\
\hline 3 to 5 years & 10 & 24.39 \\
\hline 5 to 10 years & 10 & 24.39 \\
\hline More than 10 years & 16 & 39.02 \\
\hline \multicolumn{3}{|c|}{ Panel B: Market investors (305 respondents) } \\
\hline Category & Number & Percent of total \\
\hline 1. Gender: & & \\
\hline Men & 226 & 74.10 \\
\hline Women & 79 & 25.90 \\
\hline 2. Age: & & \\
\hline $18-30$ & 76 & 24.92 \\
\hline $30-40$ & 168 & 55.08 \\
\hline $40-50$ & 49 & 16.07 \\
\hline $50-60$ & 11 & 3.61 \\
\hline $60+$ & 1 & 0.33 \\
\hline 3. Capital market investor for: & & \\
\hline Less than 3 years & 107 & 35.08 \\
\hline 3 to 5 years & 29 & 9.51 \\
\hline 5 to 10 years & 44 & 14.43 \\
\hline More than 10 years & 125 & 40.98 \\
\hline
\end{tabular}


Table 2. Cross-sectional correlation coefficients of grades within the bias-related pairs of questions

\begin{tabular}{|c|c|}
\hline \multicolumn{2}{|c|}{ Panel A: Portfolio managers (41 respondents) } \\
\hline Pair of questions & $\begin{array}{l}\text { Cross-sectional correlation coefficient between } \\
\text { the question grades }\end{array}$ \\
\hline Questions $1 \& 2$ (Disposition effect) & $-0.924 * * *$ \\
\hline Questions 3 \& 4 (Gambler's fallacy) & $0.928 * * *$ \\
\hline Questions $5 \& 6$ (Hot hand fallacy) & $0.877 * * *$ \\
\hline Questions $7 \& 8$ (Herd behavior) & $0.827 * * *$ \\
\hline Questions $9 \& 10$ (Availability heuristic) & $0.842 * * *$ \\
\hline \multicolumn{2}{|c|}{ Panel B: Market investors (305 respondents) } \\
\hline Pair of questions & $\begin{array}{l}\text { Cross-sectional correlation coefficient between } \\
\text { the question grades }\end{array}$ \\
\hline Questions $1 \& 2$ (Disposition effect) & $-0.937 * * *$ \\
\hline Questions 3 \& 4 (Gambler's fallacy) & $0.917 * * *$ \\
\hline Questions $5 \& 6$ (Hot hand fallacy) & $0.862 * * *$ \\
\hline Questions $7 \& 8$ (Herd behavior) & $0.841 * * *$ \\
\hline Questions $9 \& 10$ (Availability heuristic) & $0.842 * * *$ \\
\hline
\end{tabular}

Asterisks denote 1 -tailed p-values: ${ }^{*} p<0.10 ;{ }^{* *} p<0.05 ;{ }^{* * *} p<0.01$

Table 3. Basic descriptive statistics of "bias grades"

The table reports, by groups of participants, basic statistics of the "bias grades" calculated as follows:

$$
\begin{aligned}
& D G_{i}=G_{-} 1_{i}+6-G_{-} 2_{i} ; \quad G G_{i}=G_{-} 2_{i}+G_{-} 3_{i} ; \quad H G_{i}=G_{-} 5_{i}+G_{-} 6_{i} ; \\
& B G_{i}=G_{-} 7_{i}+G_{-} 8_{i} ; \quad A G_{i}=G_{-} 9_{i}+G_{-} 10_{i}
\end{aligned}
$$

\begin{tabular}{|c|c|c|c|c|c|}
\hline \multicolumn{6}{|c|}{ Panel A: Portfolio managers (41 respondents) } \\
\hline Statistics & $\begin{array}{l}\text { Disposition grade } \\
\qquad\left(D G_{i}\right)\end{array}$ & $\begin{array}{c}\text { Gambler's grade } \\
\qquad\left(G G_{i}\right)\end{array}$ & $\begin{array}{l}\text { Hot-hand grade } \\
\qquad\left(H G_{i}\right)\end{array}$ & $\begin{array}{c}\text { Herd (behavior) } \\
\text { grade }\left(B G_{i}\right)\end{array}$ & $\begin{array}{l}\text { Availability grade } \\
\qquad\left(A G_{i}\right)\end{array}$ \\
\hline Mean & 5.463 & 4.927 & 5.122 & 5.000 & 5.171 \\
\hline Median & 4 & 4 & 4 & 4 & 4 \\
\hline Standard Deviation & 2.873 & 3.045 & 2.750 & 2.739 & 2.801 \\
\hline Maximum & 10 & 9 & 9 & 10 & 9 \\
\hline Minimum & 2 & 2 & 2 & 2 & 2 \\
\hline Grade $\in[6,10]$, percent & 41.46 & 41.46 & 39.02 & 39.02 & 41.46 \\
\hline \multicolumn{6}{|c|}{ Panel B: Market investors (305 respondents) } \\
\hline Statistics & $\begin{array}{l}\text { Disposition grade } \\
\qquad\left(D G_{i}\right)\end{array}$ & $\begin{array}{l}\text { Gambler's grade } \\
\qquad\left(G G_{i}\right)\end{array}$ & $\begin{array}{l}\text { Hot-hand grade } \\
\qquad\left(H G_{i}\right)\end{array}$ & $\begin{array}{l}\text { Herd (behavior) } \\
\quad \operatorname{grade}\left(B G_{i}\right)\end{array}$ & $\begin{array}{l}\text { Availability grade } \\
\qquad\left(A G_{i}\right)\end{array}$ \\
\hline Mean & 5.646 & 5.105 & 5.331 & 5.243 & 5.416 \\
\hline Median & 4 & 4 & 4 & 4 & 4 \\
\hline Standard Deviation & 2.851 & 3.049 & 2.920 & 2.889 & 2.923 \\
\hline Maximum & 10 & 10 & 10 & 10 & 10 \\
\hline Minimum & 2 & 2 & 2 & 2 & 2 \\
\hline Grade $\in[6,10]$, percent & 43.93 & 41.64 & 41.64 & 41.64 & 42.62 \\
\hline
\end{tabular}

where: $G_{-} N_{i}$ is the grade (answer) given by participant $i$ for question (statement) N. 
Table 4. "Bias grades" comparison between professional and non-professional investors

The table compares interpersonal means of "bias grades", which are calculated for each participant $i$ as follows:

$$
\begin{array}{ll}
D G_{i}=G_{-} 1_{i}+6-G_{-} 2_{i} ; & G G_{i}=G_{-} 2_{i}+G_{-} 3_{i} ; \quad H G_{i}=G_{-} 5_{i}+G_{-} 6_{i} ; \\
B G_{i}=G_{-} 7_{i}+G_{-} 8_{i} ; & A G_{i}=G_{-} 9_{i}+G_{-} 10_{i}
\end{array}
$$

where: $G_{-} N_{i}$ is the grade (answer) given by participant $i$ for question (statement) $\mathrm{N}$.

between the groups of professional portfolio managers and market investors who filled in our research questionnaire on the web (non-necessarily professional).

The last row reports statistics for the test of the equality of means between the groups of participants.

\begin{tabular}{|c|c|c|c|c|c|}
\hline \multirow{2}{*}{$\begin{array}{c}\text { Group of participants } \\
\text { Number of participants) }\end{array}$} & \multicolumn{5}{|c|}{ Mean bias grades } \\
\cline { 2 - 6 } & $\begin{array}{c}\text { Disposition } \\
\text { grade } \\
\left(D G_{i}\right)\end{array}$ & $\begin{array}{c}\text { Gambler's grade } \\
\left(G G_{i}\right)\end{array}$ & $\begin{array}{c}\text { Hot-hand grade } \\
\left(H G_{i}\right)\end{array}$ & $\begin{array}{c}\text { Herd (behavior) grade } \\
\left(B G_{i}\right)\end{array}$ & $\begin{array}{c}\text { Availability grade } \\
\left(A G_{i}\right)\end{array}$ \\
\hline Portfolio managers (41) & 5.463 & 4.927 & 5.122 & 5.000 & 5.171 \\
Market investors (305) & 5.646 & 5.105 & 5.331 & 5.243 & 5.416 \\
Difference & -0.183 & -0.178 & -0.209 & -0.243 & -0.245 \\
Test of equality: & $\mathbf{0 . 3 8 ( 3 5 . 0 5 )}$ & $\mathbf{0 . 3 5}(\mathbf{3 6 . 2 8})$ & $\mathbf{0 . 4 3}$ (33.24) & $\mathbf{0 . 5 1}(\mathbf{3 0 . 5 9 )}$ & $\mathbf{0 . 5 1}(\mathbf{3 0 . 6 0 )}$ \\
t-statistic (1-tailed & & & & & \\
p-value, \%) & & & & & \\
\hline
\end{tabular}


Table 5. "Bias grades" comparison between the groups of participants, according to their investment experience

The table compares interpersonal means of "bias grades", which are calculated for each participant $i$ as follows:

$D G_{i}=G_{-} 1_{i}+6-G_{-} 2_{i} ; \quad G G_{i}=G_{-} 2_{i}+G_{-} 3_{i} ; \quad H G_{i}=G_{-} 5_{i}+G_{-} 6_{i} ;$

$B G_{i}=G_{-} 7_{i}+G_{-} 8_{i} ; \quad A G_{i}=G_{-} 9_{i}+G_{-} 10_{i}$

where: $G_{-} N_{i}$ is the grade (answer) given by participant $i$ for question (statement) $\mathrm{N}$

between the groups of participants, according to their reported stock market trading experience. We employ only the data from the subsample of participants who had answered on the web (305 participants).

The last rows of each section of the table report statistics for the tests of the equality of means between the respective categories of participants.

\begin{tabular}{|c|c|c|c|c|c|}
\hline \multirow{2}{*}{$\begin{array}{c}\text { Reported years of investment } \\
\text { experience } \\
\text { (Number of participants) }\end{array}$} & \multicolumn{5}{|c|}{ Mean bias grades } \\
\hline & $\begin{array}{l}\text { Disposition } \\
\text { grade } \\
\left(D G_{.}\right) \\
\end{array}$ & $\begin{array}{l}\text { Gambler's grade } \\
\qquad\left(G G_{i}\right)\end{array}$ & $\begin{array}{l}\text { Hot-hand grade } \\
\qquad\left(H G_{i}\right)\end{array}$ & $\begin{array}{l}\text { Herd (behavior) grade } \\
\qquad\left(B G_{i}\right)\end{array}$ & $\begin{array}{l}\text { Availability grade } \\
\qquad\left(A G_{i}\right)\end{array}$ \\
\hline Less than 3 years (107) & 8.794 & 8.374 & 8.411 & 8.271 & 8.467 \\
\hline 3 to 5 years (29) & 5.897 & 5.069 & 5.345 & 5.414 & 5.310 \\
\hline Difference & 2.897 & 3.305 & 3.066 & 2.857 & 3.157 \\
\hline Test of equality: & $10.47(0.00)$ & $8.66(0.00)$ & $8.04(0.00)$ & $7.45(0.00)$ & $7.91(0.00)$ \\
\hline \multicolumn{6}{|l|}{ t-statistic (1-tailed p-value, $\%$ ) } \\
\hline 3 to 5 years (29) & 5.897 & 5.069 & 5.345 & 5.414 & 5.310 \\
\hline 5 to 10 years (44) & 4.500 & 3.386 & 3.932 & 3.909 & 3.977 \\
\hline Difference & 1.397 & 1.683 & 1.413 & 1.505 & 1.333 \\
\hline Test of equality: & $2.79(0.34)$ & $2.79(0.34)$ & $2.53(0.68)$ & $2.57(0.62)$ & $2.33(1.14)$ \\
\hline \multicolumn{6}{|l|}{ t-statistic (1-tailed p-value, $\%$ ) } \\
\hline 5 to 10 years (44) & 4.500 & 3.386 & 3.932 & 3.909 & 3.977 \\
\hline More than 10 years $(125)$ & 3.296 & 2.920 & 3.184 & 3.080 & 3.336 \\
\hline Difference & 1.204 & 0.466 & 0.748 & 0.829 & 0.641 \\
\hline Test of equality: & $4.30(0.00)$ & $1.52(6.52)$ & $2.54(0.59)$ & $2.90(0.21)$ & $2.15(1.64)$ \\
\hline t-statistic (1-tailed p-value, \%) & & & & & \\
\hline
\end{tabular}


Table 6. "Bias grades" comparison between professional and experienced investors

The table compares interpersonal means of "bias grades", which are calculated for each participant $i$ as follows:

$$
\begin{aligned}
& D G_{i}=G_{-} 1_{i}+6-G_{-} 2_{i} ; \quad G G_{i}=G_{-} 2_{i}+G_{-} 3_{i} ; \quad H G_{i}=G_{-} 5_{i}+G_{-} 6_{i} ; \\
& B G_{i}=G_{-} 7_{i}+G_{-} 8_{i} ; \quad A G_{i}=G_{-} 9_{i}+G_{-} 10_{i}
\end{aligned}
$$

where: $G_{-} N_{i}$ is the grade (answer) given by participant $i$ for question (statement) $\mathrm{N}$

between the groups of professional portfolio managers and market investors who filled in our research questionnaire on the web (non-necessarily professional), reporting the longest stock market trading experience.

\begin{tabular}{|c|c|c|c|c|c|}
\hline \multirow{2}{*}{$\begin{array}{c}\text { Group of participants } \\
\text { (Number of participants) }\end{array}$} & \multicolumn{5}{|c|}{ Mean bias grades } \\
\hline & $\begin{array}{c}\text { Disposition } \\
\text { grade } \\
\left(D G_{i}\right) \\
\end{array}$ & $\begin{array}{l}\text { Gambler's grade } \\
\qquad\left(G G_{i}\right)\end{array}$ & $\begin{array}{l}\text { Hot-hand grade } \\
\qquad\left(H G_{i}\right)\end{array}$ & $\begin{array}{l}\text { Herd (behavior) } \\
\text { grade }\left(B G_{i}\right)\end{array}$ & $\begin{array}{l}\text { Availability grade } \\
\qquad\left(A G_{i}\right)\end{array}$ \\
\hline $\begin{array}{c}\text { Portfolio managers }(41) \\
\text { Market investors with more than } 10 \text { years of } \\
\text { trading experience }(125) \\
\text { Difference } \\
\text { Test of equality: } \\
\text { t-statistic (1-tailed p-value, } \%)\end{array}$ & $\begin{array}{c}5.463 \\
3.296 \\
2.167 \\
\mathbf{6 . 2 9}(\mathbf{0 . 0 0 )}\end{array}$ & $\begin{array}{c}4.927 \\
2.920 \\
2.007 \\
\mathbf{5 . 4 8}(\mathbf{0 . 0 0 )}\end{array}$ & $\begin{array}{c}5.122 \\
3.184 \\
1.938 \\
\mathbf{5 . 6 0 ( 0 . 0 0 )}\end{array}$ & $\begin{array}{c}5.000 \\
3.080 \\
1.920 \\
\mathbf{5 . 8 2}(\mathbf{0 . 0 0 )}\end{array}$ & $\begin{array}{c}5.171 \\
3.336 \\
1.835 \\
\mathbf{5 . 1 9 ( 0 . 0 0 )}\end{array}$ \\
\hline
\end{tabular}

The last row reports statistics for the test of the equality of means between the groups of participants.

Table 7. "Bias grades" for men and women

The table compares interpersonal means of "bias grades", which are calculated for each participant $i$ as follows:

$$
\begin{aligned}
& D G_{i}=G_{-} 1_{i}+6-G_{-} 2_{i} ; \quad G G_{i}=G_{-} 2_{i}+G_{-} 3_{i} ; \quad H G_{i}=G_{-} 5_{i}+G_{-} 6_{i} ; \\
& B G_{i}=G_{-} 7_{i}+G_{-} 8_{i} ; \quad A G_{i}=G_{-} 9_{i}+G_{-} 10_{i}
\end{aligned}
$$

where: $G_{-} N_{i}$ is the grade (answer) given by participant $i$ for question (statement) $\mathrm{N}$

\begin{tabular}{|c|c|c|c|c|c|}
\hline \multirow{2}{*}{$\begin{array}{c}\text { Gender } \\
\text { (Number of participants) }\end{array}$} & \multicolumn{5}{|c|}{ Mean bias grades } \\
\hline & $\begin{array}{l}\text { Disposition } \\
\text { grade } \\
\left(D G_{i}\right)\end{array}$ & $\begin{array}{l}\text { Gambler's grade } \\
\qquad\left(G G_{i}\right)\end{array}$ & $\begin{array}{l}\text { Hot-hand grade } \\
\qquad\left(H G_{i}\right)\end{array}$ & $\begin{array}{l}\text { Herd (behavior) grade } \\
\qquad\left(B G_{i}\right)\end{array}$ & $\begin{array}{l}\text { Availability grade } \\
\qquad\left(A G_{i}\right)\end{array}$ \\
\hline Men (226) & 4.659 & 4.177 & 4.394 & 4.301 & 4.509 \\
\hline Women (79) & 8.468 & 7.759 & 8.013 & 7.937 & 8.013 \\
\hline Difference & -3.989 & -3.582 & -3.619 & -3.636 & -3.504 \\
\hline $\begin{array}{l}\text { Test of equality: } \\
\text { t-statistic (1-tailed } \\
\text { p-value, \%) }\end{array}$ & $12.59(0.00)$ & $10.47(0.00)$ & $11.28(0.00)$ & $11.53(0.00)$ & $10.76(0.00)$ \\
\hline
\end{tabular}

for men and women. We employ only the data from the subsample of participants who had answered on the web (305 participants).

The last rows of each section of the table report statistics for the test of the equality of means.

\section{Appendix:}

\section{Research questionnaire (translated)}

1. I prefer to sell stocks whose prices recently increased. (Disposition effect)

2. I prefer to keep holding on stocks if their current market price is higher than the price I had purchased them for. (Disposition effect)

3. If in each of the last six months TA-100 Index value increased, I would expect the value of the Index to decrease in the next month. (Gambler's fallacy) (TA-100 Index tracks the prices of the shares of the 100 companies with the highest market capitalization on the Tel Aviv Stock Exchange - authors' remark)

4. If in each of the last six months TA-100 Index value decreased, I would expect the value of the Index to increase in the next month. (Gambler's fallacy) 
5. After I manage to realize a profit on my stock portfolio, I increase the sum of my stock market holdings. (Hot hand fallacy)

6. If I find out that the market price of one of the stocks I hold decreased dramatically, I decrease the sum of my stock market holdings. (Hot hand fallacy)

7. I prefer to buy stocks if many "buy" orders were submitted for them from the beginning of the trading session. (Herd behavior)

8. If in the last month, the aggregate trading volume in the stock market was higher than usual, I would increase the sum of my stock market holdings. (Herd behavior)

9. I prefer to buy stocks on the days when the value of TA-100 Index increases. (Availability heuristic)

10. I prefer to sell stocks on the days when the value of TA-100 Index decreases. (Availability heuristic) 